\title{
A FICÇÃO DE RESPEITO A AUTONOMIA INDIVIDUAL COMO FORMA DE EXPLORAÇÃO DO SUJEITO NAS PESQUISAS CLÍNICAS COM HUMANOS
}

\author{
THR FICTION OF RESPECT INDIVIDUAL AUTONOMY AS A KIND OF \\ CLÍNICAL RESEARCH HUMAN SUBJECT EXPLOTATION
}

${ }^{1}$ Natalia Petersen Nascimento Santos

\begin{abstract}
RESUMO
O presente artigo promove uma discussão em torno da concepção jurídica ocidental que concebe os indivíduos como sujeitos de direito, polemizando a conveniência de tal formulação no âmbito das pesquisas clínicas em seres humanos, posto a situação comumente limítrofe de vulnerabilidade em que se encontram os voluntários que se submetem aos referidos procedimentos. Para tanto, utilizou-se como marco teórico a obra Introdução crítica ao Direito de Michel Mialle, na qual o autor afirma de maneira contundente que a construção do instituto jurídico do sujeito de direito e a imposição do reconhecimento irrestrito da autonomia individual constituem uma construção do Estado burguês para facilitar a dominação do vulnerável, de maneira que este, mesmo não sendo juridicamente obrigado à praticar determinadas condutas, veja-se obrigado pelas circunstâncias a atuar em consonância com os interesses de tal instituição. Defende-se, desse modo, que a autonomia para consentir com a participação nos ensaios científicos deva ser aferida em cada caso concreto, com atenção especial às circunstâncias capazes de vulnerabilizar o voluntário de pesquisa e mitigar sua autonomia individual em face dos experimentos, sob pena de se estar submetendo o indivíduo à procedimentos nocivos a sua vida e saúde em prol dos interesses da sociedade de capital.
\end{abstract}

Palavras-chave: Bioética, Autonomia, Pesquisas clínicas

\footnotetext{
${ }^{1}$ Doutoranda em Direito na Universidade Federal da Bahia - UFBA, Salvador - BA (Brasil).

E-mail: nat_petersen@hotmail.com
} 


\begin{abstract}
This article promotes a discussion of western legal concept which sees individuals as subjects of rights, discussing the advisability of such a formulation in the context of clinical trials in humans, since the commonly borderline situation of vulnerability in which they are volunteers who submit to such procedures. For this purpose, it was used as a theoretical framework to work "Critical Introduction to Law" Michel Mialle, in which the author states in a forceful way that the construction of the legal institute of the "subject of law" and the imposition of unrestricted recognition of individual autonomy constitute a construction of the bourgeois state to facilitate the domination of vulnerable, so that this, although not legally obliged to practice certain behaviors, see forced by circumstances to act in line with the interests of that institution. It is argued, therefore, that autonomy to consent to participation in scientific trials must be assessed in each case, with special attention to circumstances which might vulnerabilizar voluntary research and mitigate their individual autonomy in the face of the experiments, under penalty to be subjecting the individual to harmful procedures to their lives and health for the benefit of capital society's interests.
\end{abstract}

Keywords: Bioethics, Autonomy, Clinical research 


\section{INTRODUÇÃO}

As sociedades ocidentais, na qual o Brasil se inclui, consolidaram o discurso do sujeito de direito, que percebe o indivíduo como ser autônomo e capaz de adotar suas próprias escolhas, dando aos cidadãos a impressão de serem eles senhores de suas vidas e de seus destinos.

Crianças, idosos, adultos, deficientes, ricos e pobres são igualmente elevados à categoria de livres, capazes e possuidores de uma dignidade da pessoa humana empoderadora, a qual, em tese, é uniforme, atingindo a todos. O que se contempla é sempre o respeito à autonomia individual e ao poder de escolha dos sujeitos, independentemente dos resultados da opção.

No âmbito das pesquisas clínicas isso se reflete na exigência dos órgãos de regulamentação dos experimentos de que os voluntários consintam com os ensaios, após o esclarecimento de suas etapas e riscos, autorizando, os pesquisadores e indústrias farmacêuticas a executarem experimentos potencialmente nocivos à saúde e integridade física dos experimentados.

Acredita-se que, desse modo, os voluntários estariam exercendo seu poder decisório de maneira autônoma, na medida em que saberiam dos riscos, dos benefícios e poderiam, com ambas as informações ponderar pela decisão mais conveniente a sua pessoa, ao tempo em que a maciça parte dos estudiosos do tema rechaça toda e qualquer possibilidade de mitigação do acesso de tais pesquisas a determinados indivíduos vulnerabilidades, sob a acusação de paternalismo.

Todavia, essa mesma concepção que apresenta ao indivíduo a possibilidade de agir, retira dele a proteção jurídica diante das situações em que o mesmo, embora legalmente livre para adotar escolhas, teve sua capacidade de análise das situações usurpada silenciosamente pelas mazelas sociais, decorrentes de uma lógica perversa da sociedade burguesa e do atuar negligente do Estado capitalista. Com isso, o caminho da exploração e coisificação do indivíduo torna-se livre e silencioso, alheio às suas resistências, posto que disfarçado de exercício da autonomia corroborado por um Estado que supostamente estaria a serviço de um bem comum.

Diante disso, o presente trabalho destina-se a questionar os fundamentos que sustentam a existência de uma autonomia irrestrita aos potenciais voluntários de pesquisa, percebendo tal prática como modo de facilitar a dominação do indivíduo vulnerável e método de dominação que transveste-se de um agir "politicamente correto". 


\section{DIGNIDADE DA PESSOA HUMANA E AUTONOMIA INDIVIDUAL}

Para melhor tratar do tema, faz-se necessário, inicialmente, conceituar e polemizar dois institutos básicos ao estudo do consentimento do voluntário de pesquisa, posto que a dignidade da pessoa é um pressuposto da existência da autonomia plena e de igualdade entre os indivíduos.

Dessa forma, será realizada uma breve análise em torno do princípio da dignidade da pessoa humana, passando-se para a autonomia em seu conceito filosófico, tendo em vista a conexão entre ambos os conceitos.

\subsection{Dignidade da pessoa humana}

É difícil, na contemporaneidade, existir um trabalho jurídico que não faça referência expressa à dignidade da pessoa humana, fato justificável pela importância que tal princípio possui no ordenamento jurídico nacional e por toda carga filosófica e política que carrega consigo.

No entanto, da análise atenta da jurisprudência e doutrina nacionais, resta evidenciado que, embora amplamente utilizado, este tem sido encarado como se possuísse conceito indeterminado. O mesmo princípio que, por vezes é invocado para sustentar a prevalência da liberdade religiosa em prol do direito à vida, também tem sido invocado para a situação inversa e isso ocorre com todos os direitos fundamentais. Não é sem motivos, pois, que muitos se perguntam pelo efetivo significado da dignidade da pessoa humana, instituto difícil de ser vislumbrado no caso concreto, de conceito impalpável e de complexa definição, por vezes sendo utilizado para justificar o que para muitos pode ser considerado injustificável.

Sarlet atribui a origem do valor da dignidade humana aos escritos cristãos do Antigo e do Novo Testamento, os quais indicam serem os humanos semelhantes à Deus e que, por consequência, essa condição os impediriam de serem objetivados, uma vez que possuiriam valor intrínseco pela condição (humana) (SARLET, 2012).

Em uma perspectiva filosófica e política atingida a partir da Antiguidade Clássica, é possível se verificar que, nem sempre, o valor do ser humano foi intrínseco à sua mera existência, pois a dignidade era aferida em graus, representada pela posição que se ocupava na sociedade, existindo pessoas mais dignas que outras, conforme se depreende das palavras de Sarlet (2012, p.34-36): 
[...] verifica-se que a dignidade (dignitas) da pessoa humana dizia, em regra, com a posição social ocupada pelo indivíduo e o seu grau de reconhecimento pelos demais membros da comunidade, daí poder falar-se em uma quantificação e modulação da dignidade, no sentido de se admitir a existência de pessoas mais dignas ou menos dignas. [...] quando se fala de dignidade de cargos e funções, na honra e imagem da pessoa no seu contexto social [...] a noção de dignidade da pessoa humana adquire [...] um duplo significado, visto que, por um lado o homem possui uma dignidade que decorre de sua posição mais alta na hierarquia da natureza, já que é o único ser racional dentre os animais, o que lhe assegura uma posição especial no universo (sentido absoluto de dignidade), ao passo que, já em outro sentido, relativo, a dignidade está vinculada à posição social do indivíduo, posição esta que poderá ser alterada ao longo de sua existência."

Como é possível perceber, a dignidade estava associada ao nível hierárquico que o indivíduo pertencia, sendo o acesso dos direitos fundamentais como um todo, diretamente relacionado a este. Quanto mais alta fosse a casta a que o sujeito pertencesse, mais amplos eram seus direitos fundamentais e o inverso era verdadeiro (MELLO, 2010).

Sarlet (2012) atribui à Samuel Pufendorf a elaboração de uma formulação racional da dignidade humana, com fundamento na liberdade moral, como elemento de distinção do ser humano. Todavia, aponta Immanuel Kant como o responsável pelo abandono definitivo dos elementos sacrais do conceito de dignidade. Para o autor, "autonomia e dignidade estão, [...], intrinsecamente relacionados e mutuamente imbricados, visto que a dignidade pode ser considerada como o próprio limite do exercício do direito de autonomia, ao passo que este não pode ser exercido sem o mínimo de competência ética" (SARLET, 2012.p.40)

Ricardo Maurício Freire Soares (2010), para quem o Direito consiste numa construção axiológica e teleológica que demanda a aplicação de princípios jurídicos, a dignidade representa um axioma da civilização ocidental e o fundamento concreto do direito justo, que importa num reconhecimento de uma tutela que assegure condições materiais de subsistência e dos valores espirituais do indivíduo, pois a pessoa humana encerra um fim em si mesmo, obstando sua coisificação, sua degradação e seu aviltamento, visto que por ser o único ente dotado de vontade racional, também é o único capaz de se guiar pelas próprias leis.

Nas palavras de Soares (2010, p.128):

[...] entre os diversos princípios éticos que adquiriram status constitucional nas últimas décadas, merece destaque a dignidade da pessoa humana, porquanto, na esteira do póspositivismo jurídico, evidencia-se, cada vez de modo mais patente, que o fundamento último e a própria ratio essendi de um direito justo não é outro senão o próprio homem, considerado em sua dignidade substancial de pessoa, como forma de degradação, cujo valor intrínseco, impede qualquer forma de degradação, aviltamento ou coisificação da condição humana. 
Conforme já explanado, o pensamento kantiano não restringe a dignidade somente ao exercício do direito à autonomia, mas também censura a coisificação do homem, considerandoo um fim em si mesmo, vedando sua utilização como meio. Deve-se questionar, contudo, se os dois valores kantianos devem ser entendidos e interpretados em conjunto, um complementando o outro e, portanto, a autonomia do ser digno poderia ser exercida nos limites de sua não coisificação ou se o direito ao exercício da autonomia deve figurar nessa "queda de braço" como valor prevalente, podendo o indivíduo digno, no exercício de sua autonomia plena, se autocoisificar, ou ainda, se a vedação da coisificação do indivíduo deve prevalecer em toda e qualquer circunstância.

Isso porque, em algumas situações, a inversão deste papel pode proporcionar benefícios tanto ao indivíduo que se permite coisificar, quanto à terceiros que supostamente estão utilizando-o para alcançar um fim, a exemplo do voluntário que ajuda um laboratório a descobrir a cura para sua doença, antes incurável. Seria essa relação indignificante ao sujeito? Afinal, no dia-a-dia, todos são submetidos à uma relativa coisificação, todos figuram como meio para que algo exista ou funcione e nem por isso tal atividade retira, em tese, a dignidade dos sujeitos. Ao menos, não se vêm teóricos do direito se insurgindo contra tais situações corriqueiras.

Salienta-se que, no Estado burguês, a todo momento, o indivíduo que não detém os meios de produção, encontra-se a serviço do capital, disponibilizando sua mais valia em troca de retribuições muito inferiores às que teria direito em outras circunstâncias, permitindo o acúmulo de capital da burguesia dominante, em troca do mínimo necessário para se sobreviver, o qual deveria ser assegurado pelo mesmo Estado burguês. Contudo, não se considera ou, pelo menos, não se menciona com frequência, que este sujeito tem sua dignidade reduzida ou suprimida, em que pese ser essa submissão uma espécie de coisificação.

Exemplo disso ocorre com frequência na implementação de estudos de novos fármacos, os quais, a partir do ano 2000, passaram a ser implementados em países subdesenvolvidos e em desenvolvimento, justamente em razão dos benefícios que a exploração das vulnerabilidades da população destes locais propiciaria. Aliás, os lucros com tais explorações e a indiferença dos exploradores com os benefícios angariados com o aproveitamento das mazelas das populações exploradas não é velada como se pensa.

No livro "Cobaias Humanas", de Sonia Sha, a autora aponta que investigadores clínicos chegaram a sustentar que a proteção à saúde das cobaias deveria ser eliminada, em razão da utilidade que tal medida representaria. Segundo a mesma (SHA, 2008, p.33): 
O investigador clínico Malcolm Potts, [...]. Num artigo de Fevereiro de 2000, [...] defendeu a eliminação de protecções ao nível da saúde para cobaias, nos países em vias de desenvolvimento, para acelerar os resultados dos testes para os investigadores. Parte do seu raciocínio dependia de um típico - e selectivo - fatalismo. "o mundo real é extremamente doloroso", observou. Isto é, a saúde dos doentes do mundo em vias de desenvolvimento, que agora está a provar ser valiosa para a ciência e irreversível como o pôr-do-sol.

Por óbvio, deve haver uma ponderação na percepção de pessoas como meio para alcançar algum objetivo. $\mathrm{Na}$ atualidade, as pessoas que vivem em sociedade, tendem a depender de outrem, por não serem autossuficientes, mas deve haver um limite tal "coisificação". Se ao sujeito é dada a faculdade de optar de maneira autônoma, leia-se, sem elementos coercitivos externos à vontade do agente, pela submissão ou não à atividade, dificilmente haverá uma coisificação do sujeito, embora ele esteja servindo como meio. Neste caso, o indivíduo não estará sendo submetido por um terceiro, mas participando ou executando algo em conformidade com suas próprias leis. Estará, o sujeito, agindo com liberdade.

Porém, agravar ou ignorar as vulnerabilidades individuais e oportunizar aos vulnerabilizados o advento da "escolha", consiste, sem dúvida, numa exploração e coisificação, posto que não se pode considerar que este indivíduo possui dignidade, leia-se, condições mínimas de exercer consciente e livremente sua vontade. Sem dignidade, este não pode ser considerado autônomo.

Sarlet (2012) mantém o posicionamento de que a dignidade da pessoa humana consiste na barreira para a limitação dos direitos fundamentais ligados à dignidade como moradia e liberdade individual, configurando-se, portanto, no núcleo duro dos direitos fundamentais. O autor concebe, porém, a possibilidade de que a dignidade da pessoa ou mesmo dos grupos sofra restrições, com o objetivo de se assegurar a efetividade da dignidade de terceiros, notadamente, quando os primeiros estiverem implementando ações que violem sobremaneira a dignidade de seus pares.

Sarlet utiliza como exemplo a prisão de condenados em estabelecimentos que não oferecem condições mínimas de sobrevivência digna, asseverando ainda que o brocado do direito à igualdade, o qual compele que sejam tratados iguais os iguais e de forma desigual os desiguais, na medida de suas desigualdades, permitiria a aplicação de medida violadora à dignidade dos "algozes", quando estritamente necessária.

Em que pese tal assertiva, permaneceria a dignidade da pessoa humana sendo a base limitadora da restrição dos direitos fundamentais, prevalecendo, inclusive, em hipóteses extremas, sobre o bem jurídico vida, considerado por alguns como intangível, indisponível e inalienável (SARLET, 2012). 
Fato é que o princípio da dignidade da pessoa humana está descrito no artigo $1^{\circ}$, III, da Constituição Federal e possui hierarquia pré-constitucional por integrar o grupo dos valores que fundamentam a República Federativa do Brasil, além do próprio Estado de Direito, ou, como afirma Soares (2010, p.135), consiste na “[...] norma embasadora de todo o sistema constitucional, que orienta a compreensão da totalidade do catálogo de direitos fundamentais $[\ldots]^{\prime \prime}$.

Desse modo, o Estado de Direito existiria para proporcionar aos seus cidadãos a implementação da dignidade, a qual somente se faz possível quando assegurados os direitos individuais e sociais, aptos a proporcionar o exercício da liberdade e do bem-estar destas pessoas, nos termos do Preâmbulo da norma constitucional. A análise do respeito à dignidade da pessoa humana e dos direitos fundamentais que proporcionam sua efetividade ganham especial relevância diante de situações delicadas que demandam o exercício da autonomia individual como no caso das pesquisas clínicas com seres humanos.

Tais ensaios, nos quais são investigados novos fármacos, são procedimentos perigosos, que oferecem possibilidade de danos aos indivíduos que a eles se submetem, embora também apresentam uma possibilidade de cura aos seus voluntários. Os danos que podem ser acarretados durante os ensaios podem ser irreversíveis e a aferição da autonomia individual dos voluntários se faz necessária e imprescindível, posto que um ato de disposição sem uma consciência autônoma, num mundo ético e justo, de nada deve valer. Consequentemente, a análise das condições de vida do voluntário de pesquisa e a implementação dos direitos fundamentais responsáveis por proporcionar ao indivíduo uma vida digna torna-se imprescindível. Isso porque, a exploração de determinadas condições sociais interferem diretamente na liberdade de escolha dos voluntários e transforma o termo de consentimento informado formalmente válido e materialmente viciado, devendo ser considerado sem efeitos, sob pena de se permitir que os lucros das indústrias farmacêuticas se ampararem na exploração compulsória da integridade física e psíquica de humanos fragilizados.

\subsection{Autonomia individual}


Não há como tratar a autonomia individual, ainda que de uma perspectiva bioética, sem fazer uma breve retrospectiva da questão da autonomia filosófica no ocidente. Afinal, determinar-se significa, simplificadamente, escolher, exercer o livre arbítrio, agir guiado por sua própria razão.

Este sempre foi, e provavelmente jamais deixará de ser, um dos assuntos mais polêmicos nas sociedades ocidentais. Por óbvio, dizer-se livre é atrelar-se a ideia de poder fazer escolhas, inclusive podendo afetar as necessidades do ser. Apontar um indivíduo como livre é deixa-lo mais próximo de se tornar senhor de si mesmo, num arcabouço de sociedade que viveu atrocidades ligadas à escravidão e a agressividade da destituição das rédeas do próprio destino mediante a implementação da ditadura e de outros métodos de dominação.

Exemplos destas situações são diversos e não pararam nos escritos relacionados a momentos pretéritos a Lei Aurea. Ainda depois de sua vigência, os métodos de dominação do indivíduo pelo indivíduo se aperfeiçoaram, passou-se à "categoria" do trabalho escravo, instituiu-se a ditadura, aprisionam-se, até hoje, cidadãos hipossuficientes sob pretexto de que a vida vai melhorar ou que algum benefício será instituído ou extinto.

Ser livre, na sociedade ocidental é muito caro, pois ainda é uma ideologia distante, ao menos para boa parte da população, e ser autônomo é muito mais que agir conforme a ordem imposta. Não fosse isso, a culpabilidade, no direito penal, não teria como pressuposto a autonomia do sujeito e o poder individual de atuar de outro modo. Isso nos compele a analisar brevemente o histórico da liberdade da sociedade ocidental, para que, após, seja possível travar uma discussão sobre a efetiva liberdade individual e a autodeterminação do sujeito voluntário de pesquisa no Estado burguês.

\subsection{A concepção filosófica de autonomia no ocidente}

A liberdade individual corresponde a um dos temas mais refletidos e abordados da história da filosofia. A lista de pensadores renomados que se dignaram a discutir direta ou indiretamente sobre a liberdade é extensa, alguns, inclusive, em mais de uma obra ou pensamento, outros aparentemente detiveram-se ao tema durante toda a vida. Podem ser citados como exemplo, sem maiores dificuldades, Immanuel Kant, Sartre, Heidegger, Hegel, Schopenhauer, Tomás de Aquino, Santo Agostinho, Stuart Mill, Sócrates e Aristóteles.

Justamente pela variedade e quantidade de autores que pensaram o tema, não é possível dar à liberdade um único conceito. A partir do estudo da história e filosofia da humanidade, é 
perceptível que a compreensão de liberdade sofreu modificações diversas, adequadas a cada momento e à necessidade vividos pelas sociedades, mas sempre resguardando parte de sua compreensão originária.

De acordo com Laura Souza Lima e Brito (2013), podem ser apontados, por sua vez, três momentos relevantes no estudo da liberdade: a antiguidade, a expansão do cristianismo, e a modernidade, porém por questões didáticas, o presente artigo somente abordará os pensamentos considerados de maior relevância para a conceituação da autonomia individual.

Iniciando pela antiguidade, mais detidamente a da Grécia antiga, nos sec. V e IV a. C., a palavra liberdade estava atrelada à ideia de autonomia do Estado, na medida em que o indivíduo livre seria aquele que pertencesse à uma polis livre, na condição de cidadão capaz de participação política e não escravo, visto que tal condição lhe dotava de ampla margem de discricionariedade em relação ao seu destino.

A liberdade autonomia era a capacidade do sujeito de se manifestar sobre este destino, negando-o ou aceitando-o. A condição de escravo retirava do homem sua condição de livre, pois dava a terceiro a possibilidade de gerir os acontecimentos de sua vida e lhe negava a esfera de indeterminação de sua conduta. Em último caso, a liberdade para a aceitação do próprio destino, por parte do indivíduo, poderia ser exercida através da busca pela morte, porque sempre existiria a possibilidade de escolher essa última alternativa para fugir de um acontecimento iminente, cuja escolha, aparentemente, havia sido tolhida (BRITO, 2013) ${ }^{1}$.

A palavra autonomia, por sua vez, teria sido utilizada primeiramente por Tucídides e Xenofonte, para descrever as cidades gregas e persas que se determinavam pelas próprias leis, num conceito muito próximo do que é atualmente conhecido como soberania estatal (ROCHA, 2014) . Já na Grécia antiga, Sócrates, Platão e Aristóteles chegaram a desenvolver concepções de liberdade individual, voltadas para o sujeito, que foram aperfeiçoadas e reestruturadas no decorrer dos tempos por doutrinas como o cristianismo e pela filosofia de Immanuel Kant, ícone da liberdade individual no ocidente.

\footnotetext{
1 Segundo Maria do Carmo, a liberdade poderia ser exercida através da morte. Com ela o indivíduo poderia fugir do destino vergonhoso. Isso permite que se remeta aos filmes de época, os quais ilustram muito bem essa realidade. Diversas são as representações artísticas que demonstram estórias e histórias pessoas que, para não abrir mão da liberdade, optou pela morte. É a escolha da morte em detrimento de uma vida indigna. FARIA, Maria do Carmo. A liberdade Esquecida: fundamentos ontológicos da liberdade no pensamento aristotélico. São Paulo: Loyola, 1995.p., 44.
} 
Sócrates, que viveu entre 470 e 399 a.C., desenvolveu o conceito de enkráteia, que corresponderia ao autogoverno individual, ou seja, a capacidade de agir de acordo com a própria vontade, a qual, levaria à contingência, à moderação.

Segundo Maria do Carmo Bettencourt de Farias (1995, p.177),

[...] Sócrates já não usa o termo eleuthería, tão carregado de significações políticas, mas um novo termo: enkrateia. Aorigem do termo se encontra em Kratos, poder, força física, ou kráteia, domínio, maestria. Essa palavra, [...], passa a ser empregada agora no sentido moral. A atenção se volta da eleuthería para a autodisciplina e autocontrole, mediante os quais o homem conserva sua liberdade interior não mais diante da Moíra e dos condicionamentos exteriores, mas ante as próprias paixões. [...]

[...] A enkratés passa assim a encarnar não só um novo padrão moral, mas uma nova forma de conceber a liberdade. O domínio adquirido em relação às próprias paixões, é identificado por Sócrates com o autoconhecimento.

Esse entendimento pode causar bastante espanto quando confrontado com o pensamento contemporâneo, posto que vulgarmente se reconhece a liberdade como a faculdade de agir como se quer, independentemente das consequências negativas ou positivas, não apenas para a comunidade, como também para sujeito que age.

Para os gregos, a temperança, que é a capacidade de permanecer dentro dos próprios limites, era a maior virtude do homem, ao contrário do pensamento contemporâneo ocidental que contempla a irrestrita satisfação das vontades individuais, como sendo o ápice do exercício da liberdade.

Platão desenvolveu outra ideia muito importante: a autarkéia, que se assemelha à atual compreensão de igualdade material. Segundo o seu entendimento, um sujeito que possui tudo que precisa não está submetido a ninguém, podendo-se dizer, dessa forma, que o mesmo é livre. Nesse sentido, se um indivíduo possui tudo que precisa, se ele é autossuficiente, não estará submetido a ninguém. Ao contrário, se ele precisa de qualquer coisa ou ação que pertença ou dependa de outra pessoa, sua liberdade é afetada diretamente (ROCHA, 2014).

Aristóteles, desenvolveu a ideia de eleuteria, que seria a liberdade como condição de não ser escravo, sendo, portanto capaz de agir guiado por sua vontade. A vontade, em Aristóteles, é identificada como origem da ação, que pode se originar no agente ou fora dele, sendo que, apenas no primeiro caso, ele pode ser considerado livre. Acompanhando o pensamento de Sócrates acerca da enkráteia, Aristóteles acreditava que este agir autônomo levaria o sujeito a praticar apenas condutas boas, somente sendo capaz de escolher o mal se ele ignorasse o bem ou não agisse com liberdade (ROCHA, 2014). 
Todo esse pensamento tem estreita ligação com a teoria de kantiana de liberdade, devendo-se, primeiramente, ressalvar que a liberdade, na concepção de Kant, é inerente a todo indivíduo racional, ao tempo que a liberdade dos filósofos supra referidos era condição exclusiva dos não-escravos.

A vontade em Kant é a causalidade dos seres vivos racionais, ao tempo em que a liberdade seria a propriedade da causalidade que a permite ser eficiente, independentemente de causas externas que lhe afetem. A autonomia da vontade é propriedade pela qual ela é, para si mesma, sua lei, e, no caso de intervenções externas, não se poderia mais falar em autonomia, mas em heteronômia (ROCHA, 2014).

O traço marcante da teoria de Kant é o imperativo categórico, ao qual o homem está inclinado a agir no sentido de praticar o bem. Ele acreditava numa espécie de intuição universal do bem que, embora não fosse uma lei que antecedesse à vontade e determinasse a vontade, seria alcançável por todos os seres humanos, a partir do uso da razão. Por meio do uso da racionalidade, todos os homens são capazes de vislumbrar as condutas que são boas e a mesma conduta que poderia ser considerada boa para um indivíduo, seria, necessariamente, boa para seus pares, em que pese tal lei seja criada pela vontade individual.

Por meio desse raciocínio, percebe-se que o conteúdo da liberdade sofreu uma releitura, mas não modificações bruscas em sua compreensão. A liberdade de Sócrates, Platão e Aristóteles, juntas, amparam as bases do pensamento kantiano e todas desembocam no mesmo lugar, com pequenas alterações.

O pensamento basilar da autonomia está na possibilidade do homem agir conforme suas compreensões e estímulos internos. Esse mesmo pensamento de autodeterminação ainda inspira filósofos mais recentes como, por exemplo, Heidegger e Sartre, os quais, embora tenham introduzido ao pensamento métodos diferentes e alguns elementos antes não abordados, ainda apresentam o homem livre como aquele capaz de se determinar através das escolhas realizadas por meio da ponderação de regras próprias sem a intervenção de fatores externos ao sujeito.

A concepção heideggeriana de liberdade, propõe que a liberdade depende de uma percepção do indivíduo e do que o rodeia, para que ele se compreenda também como parte do todo (HEIDEGGER, 1983). Assim, o sujeito percebe os entes que existem à sua volta e se compreende como ente em si, passando a identificar seu papel no mundo. Dessa forma, ele toma noção da importância de sua vida e da sua própria existência, quando, livre dos ídolos e das preconcepções de mundo, este consegue alcançar a verdade das coisas. Essa verdade, a compreensão clara das coisas, é sua liberdade. 
O método em destaque desenha a liberdade como uma consequência do alcance da verdade das coisas, do mundo e do indivíduo, a partir da emergência de sensações interiores que o fazem desconsiderar pressuposições impostas e visualizar o mundo e as demais coisas como realmente são. Diante disso, o ente (o indivíduo), seria capaz de adotar atitudes autônomas, sem a coação individual de qualquer nível.

Essa percepção do homem enquanto ente, todavia, não ocorre em qualquer circunstância. Para tanto, o indivíduo precisa encontrar o autêntico nada, "a negação da totalidade do ente, o absoluto não-ente" (HEIDEGGER, 1983, p.04). Esta percepção do nada seria alcançável de duas maneiras: através do tédio absoluto e através da angustia.

Sobre o primeiro, assevera o filósofo (HEIDEGGER, 1983, p.06):

Este tédio ainda está muito longe de nossa experiência quando nos entedia exclusivamente este livro ou aquele espetáculo, aquela ocupação ou este ócio. Ele desabrocha se 'a gente está entediado'. O profundo tédio, que como névoa todas as coisas, os homens e a gente mesmo com elas numa estranha indiferença. Esse tédio manifesta o ente em sua totalidade.

A angústia, por outro lado, não se confunde com o temor à alguma coisa, comumente sentido, mas sim a angústia que brota sem qualquer motivo aparente, como resta demonstrado após a leitura do trecho a seguir (HEIDEGGER, 1983, p.07):

\footnotetext{
Angústia - dizemos nós - "a gente sente-se estranho". O que suscita tal estranheza e quem é por ela afetado? Não podemos dizer diante de que a gente se sente estranho. A gente se sente totalmente assim. Todas as coisas e nós mesmos afundamo-nos numa indiferença. Isto, entretanto, não no sentido de um simples desaparecer, mas em se afastando elas se voltam para nós. Este afasta-se do ente em sua totalidade, que nos assedia na angústia, nos oprime. Não resta nenhum apoio. Só resta e nos sobrevém - na fuga do ente - este nenhum. A angústia manifesta o nada.

"Estamos suspensos" na angustia. Melhor dito: a angústia nos suspende porque ela põe em fuga o ente em sua totalidade.
}

Quando o nada é manifestado e o ente abandona-se nele, o ente se percebe em sua totalidade. Neste abandonar-se, o ente se liberta de seus ídolos e, impossibilitado de se apoiar em qualquer coisa, qualquer fato e qualquer realidade, a este é desvelada a verdade das coisas, quando, só então, o indivíduo torna-se capaz de agir livremente: "Sem a originária revelação do nada não há ser-si-mesmo, nem liberdade" (HEIDEGER, 1983, p.14).

A autonomia - identificada no texto do filósofo supra como verdade - continua sendo a capacidade de fazer escolhas sem a interferência de elementos estranhos ao indivíduo. $\mathrm{Ou}$ seja, mesmo após mais de mil anos de diferença entre os pensamentos de heidegger e os filósofos patríticos, a autonomia permanece com sua essência preservada. 
Por outro lado, Jean-Paul Sartre possui um conceito de liberdade que contempla o homem como sujeito autônomo em sua essência, cujo exercício individual da autonomia possui repercussões no todo social. No embate entre o determinismo e o livre-arbítrio, Sartre considera que o segundo não sucumbe ao primeiro, apesar da sua existência depender daquele. Isso porque, o pensador parte do pressuposto de que ambos funcionam em conjunto, sendo um, condição para a existência do outro (COX, 2007).

A liberdade estaria, para Sartre, ligada à superação, à transcendência, representaria a eterna transposição das resistências apresentadas pelo mundo aos projetos individuais (SARTRE, 2001). O diferencial de seu pensamento emana quando o filósofo reconhece as limitações impostas aos indivíduos em razão de sua classe social como aquelas desumanizantes, na medida em que o sujeito se vê privado de uma realização em virtude destas imposições. A busca do sujeito pela superação das determinações, todavia, representaria a parcela de um todo (a classe), que recusa sua situação anterior, à situação de opressão pelas oportunidades a si tolhidas.

Sartre afirma (2001, p.543): “[...] estou condenado a existir para sempre além da minha essência, além das causas e motivos dos meus atos. Estou condenado a ser livre. Isso significa que nenhum limite da minha liberdade pode ser encontrado, exceto a liberdade em si, ou se preferir, não somos livres para deixar de sermos livres".

Com essa passagem, resta bastante claro que o pensamento sartreano entendia o homem como sujeito obrigado a decidir. Nesse passo, a liberdade para o filósofo se aproxima mais uma vez do pensamento grego que compreendia que todos os sujeitos possuíam discricionariedade em relação às suas vidas. Como já exposto, em último caso, o sujeito possuía a opção de ceifa-la.

Embora reconheça a existência de condições limitantes da ação pessoal, Sartre afasta a possibilidade de que tais condições sejam capazes de obrigar o ser humano à agir de determinado modo. Aduz, ainda, que a liberdade é a componente do homem, seu elo com a sociedade e sua condição de existência (SARTRE, 2001).

Gerd Bornheim confirma que a liberdade existencialista de Sartre possui raízes filosóficas na formulação sobre a liberdade kantiana, segundo a qual, para que o indivíduo, seja considerado livre, precisaria agir racionalmente, sem intervenções exteriores, afastando qualquer satisfação pessoal das ações que o impedissem de adotar do agir racional, respeitando sempre o dever-ser, ou seja, a liberdade dos demais componentes da sociedade (GALLUPO, 2002). 
Após esta breve digressão acerca da pequena, porém relevante, parte do pensamento filosófico ocidental sobre a liberdade e autonomia individual, constatada a evolução do pensamento em torno de uma mesma essência, qual seja de que autonomia consiste em agir conforme a vontade própria individual sem coações externas, parece razoável afirmar que a autonomia, ao contrário do pensamento de Laura Souza Lima e Brito, possui um conceito firme, embora esteja em constante reanálise.

Assim, pôde-se extrair uma essência do que seria a liberdade do ponto de vista filosófico, enquanto autodeterminação do sujeito. Ademais, constatou-se ser um agir conforme as leis criadas pela vontade individual, atingidas através do emprego da razão, sem a interferência de elementos externos ao ser e com a devida temperança, a qual será a mesma para todas as esferas da vida humana.

\subsection{Autonomia bioética e pesquisas científicas}

No âmbito das pesquisas científicas, a compreensão de autonomia obtida a partir do estudo filosófico do tema também deve ser aplicada, não podendo, ao contrário do que afirma alguns pensadores, se diferenciar a autonomia em si daquela a ser utilizada para dirimir conflitos bioéticos, sob pena de se sustentar uma ficção jurídica completamente dispare da realidade, maquiando os exatos termos do contrato, apenas por uma questão de conforto psíquico.

Da compreensão de autonomia alcança, a pessoa autônoma atua sem a interferência de estímulos externos ou variáveis internas. Seria, pois, uma conduta autônoma e moral quando fosse possível a verificação de uma estrita consonância com as regras impostas pela vontade do sujeito, guiada pela razão.

A partir desse pensamento, as pessoas sobre as quais incidem fatores econômicos e sociais que alteram as suas ações não podem ser consideradas autônomas, vez que não estão sendo conduzidas por sua vontade desimpedida, mas por uma razão heterônoma.

Os precursores da bioética dos quatro princípios, Beauchamp e Childress, se dedicaram a definir a ação autônoma separada da autonomia pessoal do sujeito moral. Arguem que pessoas autônomas, utilizando a concepção kantiana de autonomia, podem praticar atitudes não autônomas e pessoas com autonomia limitada podem praticar ações autônomas. Segundo os autores, algumas pessoas possuem autonomia reduzida, não podendo agir com independência intelectual, justificando, pois, as intervenções paternalistas. 
Nessa linha, uma ação autônoma seria aquela representada por uma conduta adotada intencionalmente, com a compreensão necessária e sem influências externas que determinem ou controlem sua ação. Não haveria, assim, a possibilidade de se aplicar graus à autonomia: ou o sujeito age autonomamente e, por isso, não se faz necessária a intervenção em suas ações ou sua conduta é completamente desprovida de autonomia, incidindo sobre ela o paternalismo.

Tem-se reconhecido que o predominante ingresso do elemento da autonomia na bioética visava enfraquecer a ética paternalista que imperava nas relações médico/paciente e permitiram a ocorrência de situações bastante complexas no mundo médico, notadamente, em pesquisas clínicas. Casos polêmicos de pesquisas com humanos descritos nas publicações de Beecher, assim como o julgamento de Nuremberg e o caso Karen Ann Quilan, ${ }^{2}$ demonstraram a existência de distorções do paternalismo, promovendo, como efeito, a supervalorização da autonomia e a sustentação de sua existência indiscriminada com excessivo rigor (KOTOW, 2007).

Independentemente da existência formal do princípio da autonomia, sua aferição efetiva deve ser objeto de atenção, não apenas em respeito à autonomia individual, mas porque a constatação de uma ação autônoma na aquiescência do voluntário em participar das pesquisas clínicas possui implicações jurídicas penais e cíveis, posto que implicam num potencial ato de disposição do próprio corpo, bem jurídico, até então, considerado pela doutrina e jurisprudência majoritárias como indisponível e inalienável ${ }^{3}$.

\footnotetext{
2 O caso Karen Ann Quinlan é um dos casos mais conhecidos envolvendo eutanásia do mundo. A jovem de 22 (vinte e dois) anos, ingressou na emergência de Newton Memorial Hospital, de New Jersey/EEUU na década de 70 (setenta), em estado de coma, sem previsão de reversibilidade. Aproximadamente 4 (quatro) meses depois, sua família solicitou ao médico a retirada do respirador, tendo o mesmo se recusado a proceder tal feito o que levou a família a ingressar com ação na justiça. Apesar de ter sido negada em sede de primeiro grau, tal pleito fora deferido em sede de apelação pela Corte de New Jersey e, em meados do ano de 1976 ( mil novecentos e setenta e seis) a referida aparelhagem foi retirada, sem a qual Karen ainda sobreviveu por 9 (nove) anos. (GODIM, Caso Karen Ann Quilan, 1997)

3 Apenas a título de informação, vale salientar que Claus Roxin defende que se o bem jurídico atingido possui natureza individual e o sujeito supostamente ofendido pela conduta possui condições plenas de entender a ação injusta, não caberia ao Estado, ainda que entendesse e elegesse estes bens jurídicos como indispensáveis, punir o autor da conduta típica. Isso porque, o maior interessado na preservação destes valores (o "ofendido"), já havia demonstrado seu total desinteresse pela referida proteção. Todavia, quando se refere ao bem jurídico vida e integridade física, o referido doutrinador sustenta a impossibilidade de sua disposição, uma vez que tal conduta seria contrária aos bons costumes. Ademais, sustenta ainda que diante da existência de vícios de vontade, o consentimento prestado restaria ineficaz, ainda que o sujeito gozasse de capacidade (ROXIN, 2008). O fundamento da exclusão de responsabilidade pela existência da aceitação do ofendido tem origem na teoria liberal de que se os bens jurídicos são instituídos a fim de propiciar o desenvolvimento do indivíduo, não havendo a possibilidade de se sustentar lesão em face dos bens que o próprio portador dispôs. Resta evidenciado, então, que a constatação da autonomia individual possui implicação direta na responsabilização do agente "agressor", o que torna a aferição da autonomia individual uma tarefa de extrema relevância.
} 
Viviane Grimm, partindo do pressuposto de que a construção de um indivíduo autônomo é uma formulação imposta pela Sociedade de Controle, entende o discurso da autonomia como uma questão de "governamentabilidade”. Segundo a autora, a partir da leitura das teorias de Foucaut, esse processo de suposta construção da autonomia pode ser uma estratégia para gerir os sujeitos e as populações, pois, ao mesmo tempo que a ideia do sujeito autônomo propicia a autodeterminação, poderia proporcionar ao Estado maior controle sobre os cidadãos. O resumo de um estudo realizado pela supra referida autora pode desencadear uma importante reflexão. Em análise de campo, realizada através da aplicação de entrevistas em alunos do ensino médio com a respectiva análise qualitativa das respostas, a mesma identificou que a maioria dos entrevistados apontou o desenvolvimento da autonomia como sendo um objetivo do ensino escolar (GRIMM, 2005). Entretanto, a estimulação e o nascimento de tal instituto sempre estiveram acompanhados de uma obrigação. A autodeterminação, na escola, está inserida num discurso que presa não só pelo desenvolvimento no indivíduo de sua capacidade de se determinar, mas que estas escolhas observem deveres, regras e limites, facilitando, portanto, a inserção Estatal dos mecanismos de controle. O discurso é: você pode escolher, entretanto, se não houverem vedações, dentro dos limites impostos e depois de cumprir suas obrigações (GRIMM, 2005).

Da mesma forma que este raciocínio é conveniente para a governabilidade de um Estado, inculcando em seus cidadãos a noção de um falso livre arbítrio, que só é livre em abstrato, mas concretamente não existe por fatores legais, morais, econômicos, espaciais e sociais, o inverso também pode ser pode ser conveniente ao Estado, em relação a práticas outras, entre as quais estão as pesquisas clínicas em seres humanos.

Não seria o discurso da existência de uma autonomia absoluta uma tática desleal para legitimar as pesquisas clínicas, e, sutilmente, permitir que as grandes indústrias farmacêuticas dominem os voluntários nas pesquisas de novos agentes?

\section{A FANTASIA DO SUJEITO DE DIREITO SEGUNDO MICHEL MIALLE}

Em que pese toda a discussão travada no capítulo anterior em torno do conceito de dignidade da pessoa humana e da autonomia, considerando que o primeiro, e, por consequência lógica, o segundo, constitui fundamento do Estado Democrático de Direito, elencado no preâmbulo da Constituição Federal, tais conceitos precisam ser analisados por outra perspectiva, 
deslocando-os da pura apreciação jurídica para a confrontação com sua correlação histórica e sociológica.

Michel Mialle, em seu livro "Introdução crítica ao Direito" polemiza conceitos tidos como naturais no cotidiano jurídico, os quais são constantemente negligenciados no ensino da introdução do estudo do direito, de modo a prejudicar a real percepção do introduzido, em relação a instituições e institutos basilares que compõem a matéria. Em sua abordagem, partindo de uma teorização amparada numa reflexão marxista, Miale discorre sobre o conceito e fundamento difundido de Estado e de sujeito de direito, apresentando concepções valiosas, não apenas para a percepção de uma disciplina introdutória geral, mas também importantes na apreciação da autonomia do sujeito para anuir a pesquisas clínicas conforme se demonstrará a seguir.

\subsection{O Estado como fonte do Direito e a promoção do bem comum}

Quando se discute a função das leis e do Direito, para uma compreensão mais crítica, na concepção de Miale, deve-se considerar como pressuposto uma realidade por vezes esquecida, mas que pode clarificar a fonte e o fundamento de diversos problemas, inclusive em relação à postura dos Estados diante das pesquisas clínicas de novos fármacos, auxiliando na compreensão das diversas falhas legislativas, fiscalizadoras e no empenho de tal maquinário para desburocratizar os ensaios e valorizar sobremaneira a suposta autonomia dos potenciais voluntários de pesquisa.

O ponto de partida deve ser, segundo Miale, inexoravelmente, o de que a lei provém da vontade do Estado, o qual promove o respeito a esse direito produzido através de uma sanção.

Esse pressuposto, embora seja bastante óbvio, por vezes se perde na ilusão jurídica de que a norma revelaria uma vontade geral externada pela sociedade, como se o Estado fosse, portanto, um servo dessa comunidade, vinculado, necessariamente, às necessidades de seus integrantes.

Não raras vezes o cidadão, principalmente no Brasil, depara-se com decisões legislativas e elaboração de normas que confrontam absurdamente o senso de justiça e proporcionalidade da maioria, fazendo pouco caso aos interesses desses indivíduos, afrontando, portanto, a representação da suposta vontade universal.

Na contemporaneidade, no Estado brasileiro, podem ser apontadas as recentes medidas de redução dos benefícios trabalhistas, o aumento nas exigências para deferimento de auxílio 
desemprego, a elevação de determinados impostos, o deferimento questionável do benefício de auxílio moradia para os magistrados, a recente aprovação da redução da maioridade penal. Todas estas medidas adotadas pelo Estado, confrontavam, ao menos, o senso de justiça de metade da população e ainda assim foram impostas.

Outras situações como a recente Projeto de Lei 200/2015, da senadora Ana Amélia do PP-RS, que propõe uma desburocratização e agilização dos procedimentos de autorização dos protocolos de pesquisa, são iniciativas estatais que, embora não contrariem diretamente os interesses da população (posto que esta não compreende a gravidade da medida e não tem seu cotidiano afetado diretamente), o fazem indiretamente de maneira velada.

O referido projeto, é vendido como uma maneira de agilizar a liberação de protocolos de pesquisa, sob a desculpa de que isso forneceria aos pacientes uma melhor condição de tratamentos e contribuiria para a saúde pública (BRASIL, SENADO NOTÍCIAS), como se procedimentos experimentais, que apresentam riscos à saúde de seus pesquisados pusessem ser considerados efetivos tratamentos e ignorando que as maiores beneficiadas com a desburocratização dos protocolos de experimentos e a redução dos mecanismos de controle são os laboratórios que desenvolvem as novas drogas e suas financiadoras, uma vez que um menor prazo para o recebimento dos resultados significa a percepção mais ágil dos lucros potenciais.

Essa ilusão em relação à motivação do Direito ganha força diante do art. $1^{\circ}$, a Constituição Federal de 1988, o qual afirma que a dignidade da pessoa humana é um dos fundamentos do Estado Democrático de Direito, acompanhado pelo que dispõe seu preâmbulo, posto que afirma, sem maiores rodeios, ser o fim deste Estado a garantia "do exercício dos direitos sociais e individuais, a liberdade, a segurança, o bem-estar, o desenvolvimento, a igualdade e a justiça como valores supremos de uma sociedade fraterna, pluralista e sem preconceitos, fundada na harmonia social e comprometida, na ordem interna e internacional, com a solução pacífica das controvérsias” (CONSTITUIÇÃO, 1988).

Tal concepção remete o jurista, de acordo com Mialle (MIALLE, 2005), à percepção hegeliana de Estado. Em sua teoria, Hegel compreende o referido ente como ser ético, destinado a harmonizar as tensões existentes entre as vontades individuais e o bem comum, transcendendo a sociedade civil.

À sociedade civil competiria a mediação das liberdades individuais, mas que sucumbiria à crise social resultante da diferença de classe de ricos e pobres, uma vez que a pura urgência de satisfação das necessidades recíprocas não seria suficiente para evitar o colapso decorrente das desigualdades. Em razão disso, o Estado surgiria como um sujeito ético 
imprescindível e despersonalizado, que teria como fundamento e função a preservação do bem comum pautado na vontade geral (HEGEL, 1998).

De acordo com Mialle (2005, p.125-126),

\begin{abstract}
A reunião dos homens exige que seja encontrada uma ordem que possa, se necessário, impor-se pela força. Essa ordem será a do direito: essa força será a do Estado. Mas nem essa força, nem essa ordem são arbitrárias: elas são legitimadas pelo "bem comum" que querem instaurar. [...]

O Estado aparece com a realidade em que o indivíduo tem a sua liberdade e goza dela enquanto saber, fé e querer geral.

Ele constitui assim, o elo final de uma cadeia cujo conteúdo é a consciência da liberdade: o Estado reconcilia o particular e o universal dando ao indivíduo a moralidade objetiva. O Estado é, então, face aos interesses privados, uma necessidade, a que, unindo vontade particular e vontade universal, permite ao homem encontrar uma plena realização, a do reconhecimento do seu próprio Espírito.
\end{abstract}

O problema consiste, todavia, em ignorar quem são os sujeitos que aparelham o Estado moldando, portanto, a referida vontade geral. A sociedade capitalista, conforme sustentado por autores como Miale e Marx, submete-se à dominação econômica dos sujeitos detentores dos meios de produção, os quais coincidem com os mesmos sujeitos que investem o Estado, condicionando seu funcionamento à promoção dos interesses particulares. Assim, os detentores do capital não se limitam em dominar e moldar as práticas econômicas, eles também se tornam detentores do poder político, ou seja, do poder do Estado.

Em 1912, Vladimir Lênin já afirmava que,

Os fatos da democracia não devem fazer-nos perder de vista a circunstância, frequentemente negligenciadas pelos democratas burgueses, que nos países capitalistas as instituições representativas inevitavelmente cedem lugar para formas específicas aonde o capital exerce sua influência sobre o poder estatal. Nós não temos um parlamento, mas não há fim para o cretinismo parlamentar entre os liberais e licença parlamentar entre seus cúmplices burgueses.

Desse modo, o capital comanda o Estado, que por sua vez, é quem define as normas jurídicas e impõe sua aplicação por meio da força. O Estado proibirá e permitirá condutas e adotará posições convenientes aos interesses do capital em todas as suas esferas, uma vez que não se trata apenas de um Estado, mas de um ente a serviço da burguesia.

Melindra-se, pois, a concepção inocente de um ente ético a serviço da promoção do bem geral e, por sua vez, quando se aprecia os demais institutos de Direito, não se pode distanciar desta noção basilar, seja para a análise de uma política econômica, seja para a compreensão da dignidade da pessoa humana ou mesmo do que vem a consistir o atual conceito de sujeito de direito. 


\subsection{O sujeito de direito como uma ficção no Estado Democrático}

A análise da dignidade da pessoa humana permitiu o desvelar de uma concepção ontológica do que seria este instituto e quais seriam suas consequências. Compreendeu-se, a partir do conceito kantiano, que esse postulado traria consigo a valorização de todos os indivíduos em razão da simples condição humana e que, dessa forma, seria intolerável a supressão do poder decisório de um indivíduo pelo outro.

Notadamente, se todos são iguais não há motivo para que a opinião de determinadas pessoas possa se sobrepor à opinião de outras, pois, dessa forma, os discursos teriam valores diferentes e se concluiria que determinados tipos de pessoas teriam valores diversos de outras. Justamente por isso, todo indivíduo deve, segundo essa concepção, ser considerado e tratado como autônomo, como capaz de decidir os rumos de sua vida, sem que outros sujeitos intervenham coercitivamente, vez que, se são todos iguais, uma opinião não deve valer mais que outra, ao menos quando se trata de optar pelos rumos da própria vida.

Ocorre, porém, que o Estado que elencou essa dignidade no art. $1^{\circ}$ de sua constituição e que tem adotado a supervalorização da autonomia individual em situações limítrofes, é um Estado que se encontra a serviço do capital, ou seja, um Estado burguês, e suas normas devem ser interpretadas, considerando tal questão.

Diante disso, faz-se imprescindível o questionamento em torno da conveniência do discurso que trata todos os indivíduos como sujeitos de direito e autônomos em sua plenitude, desconsiderando, pois, os elementos da vida social capazes de provocar vulnerabilidades que atinjam diretamente este indivíduo e seu poder de adotar decisões livres. Deve-se perguntar, pois, a quem a pressuposição ilimitada de autonomia está a serviço?

Para iniciar esse questionamento com mais propriedade, faz-se imprescindível apontar novamente a crítica de Michel Mialle em torno da conceituação do que seria o sujeito de direito, amplamente difundida nos cursos de introdução ao estudo da norma.

Segundo tal autor, a forma acrítica como é passada a conceituação do sujeito de direito, permite ocultar o caráter artificial desse conceito e a função que exerce na sociedade burguesa. Para a concepção largamente utilizada, todo homem seria sujeito de direito, instituto que decorreria diretamente da personalidade jurídica do homem. Levando em conta esse raciocínio, todo indivíduo, em regra, corresponderia a um sujeito de direito (MIALLE, 2005). 
Mialle (2005) assevera, contudo, haver uma falha nessa compreensão, assim como na compreensão de que todo sujeito seria autônomo para decidir como iguais, na medida em que nem todos estão submetidos às mesmas condições de empoderamento. De uma perspectiva histórica, justamente porque sempre existiu a dualidade oprimidos e opressores, determinados indivíduos eram considerados sujeitos de direito, ao tempo em que outros não.

$\mathrm{Na}$ antiguidade, por exemplo, os escravos, reduzidos à condição de coisa, não detinham a liberdade de vender, comprar, emprestar ou realizar qualquer outra operação civil, o que lhes retirava a condição de sujeitos de direito (MIALLE, 2005). Igualmente, no feudalismo, os sujeitos de direito eram aqueles que detinham as terras, os senhores feudais, não havendo como se sustentar uma igualdade de direitos entre estes e os servos, por exemplo.

Esta disparidade de condições não foi suprimida com o passar dos anos. Em que pese a alteração das cidades e as formas de relação que surgiram com o advento da modernidade e as novidades da contemporaneidade, não se pode afirmar que todos os sujeitos de uma mesma sociedade gozam dos mesmos direitos e privilégios, quando se retira a discussão do campo do dever-ser.

Assim como na antiguidade o poder decisório de um escravo era suprimido pelo seu dono e nas comunidades feudais o servo não podia adotar determinado tipo de posição em razão da ausência de certas condições (a exemplo da ausência de propriedade das terras que compunham o feudo), na contemporaneidade não se pode arguir que o sujeito esteja juridicamente obrigado a adotar determinadas posturas e opções, mas, por vezes, a ausência de sua capacidade de decisão decorre de circunstâncias fáticas limitadoras de seu poder de escolha, compelindo-o inconscientemente a agir de determinado modo.

A hipotética igualdade de condição, que destoa da realidade e da compreensão que se extrai da norma, faz emergir um importante questionamento: "porque é que é necessário que todos os indivíduos sejam sujeitos de direito, já que a história mostra que esta situação está longe de ser evidente? Se, hoje, todos os indivíduos são sujeitos de direito, que função desempenha esta forma jurídica?" (MIALLE, 2005, p. 115).

Seria o fato da sociedade contemporânea não admitir as desigualdades entre os indivíduos ou existem motivos outros não tão claros como deveriam? Será que as instituições que ingressam em comunidades carentes e arrasadas pela falta de água, esgotamento, emprego e atenção básica à saúde, oferecendo seus tratamentos experimentais de segurança duvidosa a título de ajuda, podem considerar a adesão destes indivíduos, indiscriminadamente, como autônoma? 
O observador minimamente prudente considerará que não, visto os fatores que influem na decisão individual do voluntário, mas então, por qual motivo o Estado defende a indiscriminada autonomia e o respeito incondicional às decisões adotadas por tais sujeitos, bem como aos termos de consentimento assinados por eles?

Para Mialle (2005, p.117),

[...]declarar que todos os homens são sujeitos de direito livres e iguais não constitui um progresso em si. Significa tão-somente que o modo de produção da vida social mudou. [...] a noção de sujeito de direito como equivalente à de indivíduo está longe de ser evidente conforme o sistema social no qual nos situamos. Não é natural que todos os homens sejam sujeitos de direito. Isto é o efeito de uma estrutura social bem determinada: a sociedade capitalista. Mas, então, porque é que isso é necessário nesta sociedade? Precisamente, para permitir a realização das trocas mescantis generalizadas.

O capitalismo sobrevive do processo de valorização do capital, que se dá através da percepção da mais valia do trabalhador. O dono dos meios de produção submete o detentor da força de trabalho a determinada forma de produção, recebendo os rendimentos decorrentes desse trabalho e repassando para o proletariado valor razoavelmente inferior ao que este receberia caso comercializasse seus produtos e serviços de maneira independente. Em outras palavras, os detentores dos meios de produção exploram o trabalhador, percebendo valiosas quantias através das atividades laborais, repassando a este sujeito apenas o mínimo necessário para a sua sobrevivência.

Deve-se ressaltar que, embora estes indivíduos não estejam juridicamente obrigados a se submeterem à lógica do capital, permitindo a exploração de sua mão de obra e a apropriação da sua mais valia, o contexto fático de restrição da detenção dos meios de produção e a estruturação das sociedades atuais que privilegiam institutos como a propriedade privada, são responsáveis por obrigar tais sujeitos a observarem as exigências do capital. Sem uma terra para cultivar ou um espaço para morar, não restam muitas alternativas para aquele que não deseja se submeter à sociedade capitalista.

O mesmo acontece com o indivíduo doente, que não possui os meios de tratamento, encontra-se vulnerabilizado pela negligência do aparato do Estado, de forma que sua participação ao projeto de pesquisa se torna compulsório, com ares de facultativo. O sujeito não está juridicamente obrigado à participação, mas se encontra psíquica e materialmente obrigado a se voluntariar.

Em ambas as situações, o status de livre de um indivíduo permite que sua exploração tenha pouca resistência, na medida em que a imposição não é diretamente realizada, mas decorre de um conjunto de fatores ocultamente ligados aos detentores do capital. Se a disposição da 
força de trabalho ou de sua integridade física decorrem de um suposto ato de liberdade, adotado através do exercício da autonomia da vontade, pouco há que se questionar em relação aos riscos assumidos durante as pesquisas e bem como em relação à percepção da mais valia por parte da sociedade dominante.

Esse mecanismo pode ser aplicado de maneira análoga a todas as esferas de relacionamento que dependem de uma dominação sutil, com o mínimo de resistência e questionamento de seus resultados.

Nas próprias relações disciplinadas pelo direito público, tal empoderamento também produz seus efeitos favoráveis ao capital. Todas as vezes que um sujeito vulnerabilizado tem sua autonomia fictamente reconhecida, tal condição servirá em momento oportuno para desestruturar um possível questionamento em torno da validade do contrato firmado, pois os sujeitos são considerados autônomos e capazes de adotar decisões, pressupondo-se que o indivíduo, ainda que anuindo em acordo que lhe proporcione desvantagem, possuía plena capacidade de formar resistência e identificar os termos a si desfavoráveis, de modo que as cláusulas e condições serão interpretadas como consentidas, na medida em que o sujeito possuía o direito e a autonomia necessários para recusar tal adesão.

O reconhecimento da autonomia individual de qualquer sujeito, acaba desonerando o Estado de sua obrigação de fiscalizar o cumprimento de princípios básicos, posto que, aliada à autonomia, o indivíduo adquire capacidade para dispor de bens jurídicos individuais, desde que não sejam considerados indisponíveis ou inalienáveis.

\subsection{A ficção da autonomia individual e as pesquisas clínicas em seres humanos}

Nos últimos quarenta anos, um elevado número de medicamentos teve seu registro para circulação cassado, em razão de apresentarem reações adversas não indicadas nos ensaios que os antecederam, causando assim um endurecimento nas exigências necessárias para o cadastramento de novos produtos, principalmente nos países europeus e nos estados norte americanos. Em contrapartida, as empresas que permaneceram investindo no ramo passaram a enrijecer os critérios necessários para o deferimento das verbas, com vistas a evitar prejuízos e assegurar o retorno financeiro.

Como os ensaios finais dos estudos são mais dispendiosos e prolongados, a sua implementação em países desenvolvidos revelou-se custosa, sendo transferida para países emergentes como Brasil, e África do Sul e diversos outros da Ásia, pois, além de possuírem 
grau de desenvolvimento científico razoável, oferecem procedimentos com menores custos e rápida captação de voluntários que desejem se submeter aos experimentos (GOMES, PIMENTEL, LANDIM, PIERONI, 2012).

Não obstante os benefícios econômicos e biotecnológicos que podem ser atingidos com a absolvição de uma parcela significativa do referido mercado pelo Estado brasileiro, este fenômeno deve ser bem pensado e planejado, uma vez que os problemas estruturais do país tornam sua população demasiadamente vulnerável e relativamente despreparada frente às possíveis propostas de participação de pesquisas clínicas.

Assim como a ficção da autonomia individual, reconhecida de forma irrestrita aos componentes de uma sociedade independentemente de suas reais condições, revela-se conveniente ao Estado burguês, tal compreensão, no âmbito das pesquisas clínicas possui configuração aproximada e está, igualmente, a serviço do capital.

É impossível ignorar que os voluntários de pesquisa, em sua maioria, embora não estejam juridicamente obrigados a participar dos estudos científicos, estão submetidos à condições reais que os obrigam, quase sempre, à se submeterem aos estudos. Se por um lado o Estado Democrático de Direito reconhece a autonomia individual dos sujeitos que compõe a comunidade, por outro, não há, por parte do ente, a adoção de medidas eficazes, capazes de suprimir as vulnerabilidades agravadas de cada sujeito. Saúde, moradia, educação, acesso aos meios de comunicação e meios de erradicação da fome são problemas que assolam a sociedade brasileira e reduzem as condições de autonomia de seus integrantes.

Os fatores supra referidos são descritos, por Amartya Sen (2010), como condições de liberdades instrumentais. Para o autor, existiriam cinco esferas principais de liberdade (liberdades políticas, facilidades econômicas, oportunidades sociais, garantia de transparência e segurança protetora), ligadas entre si numa relação de dependência e a concretização de todas elas permitiria ao indivíduo uma participação social mais completa.

Enquanto as liberdades políticas consistiram na possibilidade de fiscalizar e criticar as autoridades, bem como escolher conscientemente seus governantes, as facilidades econômicas consistiriam nas "oportunidades que os indivíduos têm para utilizar recursos econômicos com o propósito de consumo, produção e troca" (SEN, 2010, p.59), mas são as oportunidades sociais a esfera de liberdade instrumental que mais afeta exercício das demais liberdades, inclusive a política. 
De acordo com Sen (2010, p.59-60),

Oportunidades sociais são as disposições que a sociedade estabelece nas áreas de educação, saúde etc., as quais influenciam a liberdade substantiva de o indivíduo viver melhor. Essas facilidades são importantes não só para a condução da vida privada (como por exemplo levar uma vida saudável, livrando-se da morbidez evitável e da morte prematura), mas também para uma participação mais efetiva em atividades econômicas e políticas. Por exemplo, o analfabetismo pode ser uma barreira formidável à participação em atividades econômicas que requeiram produção segundo especificações ou que exijam rigoroso controle de qualidade [...]. De modo semelhante, a participação política pode ser tolhida pela incapacidade de ler jornais ou de comunicarse por escrito com outros indivíduos envolvidos em atividades políticas.

Desse modo, os sujeitos submetidos a tais circunstâncias, no seio do Estado Democrático de Direito que reconhece a liberdade irrestrita e plena dos indivíduos como sujeitos de direito, adquirem a capacidade jurídica de decidir, sem, contudo, possuir condições reais de fazê-lo sem a interferência de fatores externos, posto que se encontram vulnerabilizados em suas liberdades substantivas.

Isso é ideal para o mercado de experimento de novos fármacos, uma vez que sociedades como o Brasil conseguem abrigar, num mesmo território, indivíduos susceptíveis à participação das pesquisas e o desenvolvimento tecnológico necessário para a implementação dos estudos, permitindo que estes se desenvolvam de maneira muito mais rentável e menos dispendiosa. Não é por acaso que a Índia é um dos principais destinos de tais ensaios.

No Brasil, as péssimas condições do Sistema Único de Saúde são, sem dúvida, uma das circunstâncias preponderantes para o agravamento das vulnerabilidades individuais de qualquer sujeito que não tenha, ao menos, a opção de contratar um plano de saúde particular. As grandes filas do SUS para marcação de consultas e exames essenciais são capazes de levar qualquer indivíduo ao descontrole emocional, fazendo-o, ainda que esta não fosse uma opção em outras circunstâncias, cogitar a adesão aos experimentos científicos.

O mesmo acontecerá aos sujeitos que, desprovidos de um meio digno de sustento, depararem-se com a necessidade de aquisição de dinheiro, caso tais pesquisas sejam realizadas mediante contraprestação pecuniária, dentre muitas outras situações de vulnerabilidade que podem ser agravadas pela própria economia a serviço do capital.

Exemplo bastante simbólico foi a pesquisa desenvolvida para o estudo da Malária, descoberta em 2003 pelo Ministério Público do Amapá. Segundo a Promotoria de Santana Amapá, O Instituto Nacional de Saúde dos Estados Unidos, em conjunto com a Universidade da Flórida, da Fundação Oswaldo Cruz, da Universidade de São Paulo, da Fundação Nacional de Saúde e da Secretaria Estadual de Saúde do Amapá, iniciaram uma pesquisa na comunidade 
de Pirativa, em 2003, com fim de analisar os tipos de transmissões da malária na região. (SANTOS, SANTOS, 2011)

Ocorre que a pesquisa submetia os ribeirinhos à picadas de mosquito infectados. Os voluntários alimentavam os insetos com o próprio sangue e, por esse trabalho, recebiam o equivalente à $\mathrm{R} \$ 12,00$ (doze reais) por dia. Os sujeitos que com muita dificuldade conseguiam desenhar o nome, o fizeram no contrato, segundo o qual a pessoa seria voluntária para alimentar mosquitos nos braços e pernas "para o estudo de marcação e recaptura" (SANTOS, SANTOS, 2001, p.147).

Salienta-se que Pirativa é uma comunidade formada de 175 habitantes pescadores e agricultores, para os quais, provavelmente, o valor de $\mathrm{R} \$ 12,00$ (doze reais) por dia mostravase bastante proveitoso ao tempo em que consistia numa bagatela aos financiadores das pesquisas, os quais, gastariam muito mais se o mesmo estudo fosse proposto à pessoas menos vulnerábilizadas.

Evidente que os patrocinadores da referida pesquisa exploraram as diversas suscetibilidades dos ribeirinhos - a superficial (ou inexistente) educação formal e a situação de pobreza - para desenvolver os estudos, utilizando de todos os mecanismos possíveis para reduzir as defesas dos mesmos: utilizaram linguagem inacessível e ofereceram pagamentos miseráveis, porém atrativos aos que vivem a beira da miséria.

Não fossem as irregularidades procedimentais da pesquisa e a contraprestação oferecida (a qual ainda é vedada no Brasil), o referido procedimento seria considerado legal e não teria sido interrompido, vez que tais indivíduos são considerados pela Constituição Federal e pela legislação ordinária sujeitos de direitos.

O importante é observar que, da mesma forma que os ribeirinhos foram captados pela remuneração, submetendo-se à adquirir a malária, outras podem ser as moedas de troca oferecidas, as quais, nem sempre estarão vedadas pela lei. Esse é o caso, por exemplo, do sujeito pobre, submetido ao sistema de saúde estatal que se descobre acometido por uma doença grave como câncer e tem seu primeiro exame marcado para uma data distante. Caso esse sujeito seja convidado para participar de um estudo científico que investiga novos tratamentos ou a cura para sua enfermidade, ainda que este seja conscientizado dos perigos da submissão, as mazelas decorrentes da péssima gestão do Estado burguês será fator relevante na anuência em participar do estudo, pois muito pior que a possibilidade do perigo é a certeza de não ter à disposição tratamento algum. 
O Estado burguês aglomera as duas condições necessárias para a perfeita acomodação desse mercado milionário, quais sejam, o desenvolvimento tecnológico e uma gama infinita de indivíduos que sofrem com as carências sociais e que, por sua vez, estão na busca desesperada de oportunidades para suprir, ainda que minimamente, os déficits produzidos pelo capitalismo, ocasionando o barateamento dos procedimentos.

Enquanto os ensaios mostram-se altamente dispendiosos em países centrais, vez que a busca pela participação, em geral, dá-se por razões de complementação financeira, necessitando, pois, de uma contraprestação pecuniária lucrativa, em países como o Brasil, cujas precariedades abandonam o indivíduo à própria sorte, a mera participação das pesquisas consiste numa esperança de tratamento para o voluntário, configurando, por si só, o benefício a ser alcançado.

Note-se que não se questiona a existência de efetivos benefícios em tais situações, mas tão só o valor atribuído à anuência individual, posto que, apesar de possuir o status de autônomo, os fatores do dia-a-dia impedem a conclusão absoluta e pressuposta de autonomia plena, tornando questionável os fundamentos que impõem tal condição, indiscriminadamente, a qualquer sujeito. O indivíduo que, valendo-se da condição de sujeito de direito, concorda em participar do experimento, posteriormente, não poderá questionar, em tese, caso advenham complicações dos estudos, visto que este é reconhecido como autônomo e como tal, deve ter suas opiniões e decisões respeitadas. Ocorre, todavia, que o poder de decidir não é apenas um direito, ele é acompanhado pela obrigação de suportar o peso das próprias escolhas, afastando, assim, a responsabilidade do pesquisador (que evidentemente é um representante da burguesia) e igualmente a de fiscalização e responsabilidade do Estado (que possui suas estruturas aparelhadas para servir à classe social burguesa) (MIALLE, 2005). Ou seja, o sujeito é compelido a aquiescer com um procedimento, do qual não pode questionar seus parâmetros e suas consequências, em razão da relação criada ter nascido de uma decisão autônoma e livre.

\section{CONCLUSÃO}

A dignidade da pessoa humana e a autonomia individual consistem em valores do Estado Democrático de Direito e servem de base para os demais direitos fundamentais elencados na constituição e passíveis de proteção constitucional.

Por dignidade da pessoa humana se compreendeu o valor atribuído a todos os sujeitos que compõem a sociedade, de igual modo, em razão da simples condição humana, vedando-se 
a discriminação por qualquer motivo. A autonomia, por seu turno, consistiria na capacidade do indivíduo de adotar decisões guiadas pela sua vontade autônoma, sem a interferência de valores externos ao ser. O reconhecimento da autonomia seria consequência lógica do valor intrínseco dos indivíduos pela condição de humanos, diante do reconhecimento da racionalidade inerente a tal condição.

Tais valores devem nortear qualquer conduta adotada pelo Estado e pelos particulares, a fim de que não sejam estes violados, em qualquer circunstância. Desse modo, revela-se necessária a observância dos mesmos diante da anuência do voluntário de pesquisa, devendo a autonomia do sujeito ser apreciada no caso concreto, sob pena de se objetivar o sujeito a pretexto de respeitar uma suposta autonomia universal, aproveitando-se da vulnerabilidade pessoal do mesmo em prol dos interesses da sociedade de capital.

As indústrias farmacêuticas, que se utilizam dos métodos de ensaios científicos a fim de desenvolver seus novos medicamentos, são responsáveis pela movimentação de grandes volumes de capital e a maior interessada no reconhecimento da autonomia de forma universal e indiscriminada, posto que isso ocasionaria uma desburocratização dos procedimentos ligados aos experimentos. Além disso, corresponde a uma agilização dos procedimentos científicos o reconhecimento universal da dignidade e autonomia dos sujeitos que compõem determinada sociedade. Tal situação ainda permite a redução das exigências estatais em torno dos procedimentos e a, conveniente, a redução dos riscos de indenização a que estão passíveis os pesquisadores e as empresas financiadoras, visto que, como o próprio nome já diz, os voluntários participam voluntariamente e conscientemente dos ensaios (ao menos em tese).

Reconhecendo que a presente circunstância universal não corresponde à realidade, visto que, como apontado supra, os voluntários de pesquisa em geral são indivíduos que sofrem uma série de vulnerabilidades de ordem econômica, intelectual, física e psíquica, o presente artigo buscou alertar para o risco de se presumir a autonomia indiscriminada dos sujeitos que compõem a sociedade. Com isso, desmistifica-se o aspecto puramente positivo do discurso que iguala os indivíduos juridicamente, a fim de que as vulnerabilidades dos voluntários não sejam exploradas de maneira acrítica e maquiada, preservando os indivíduos cuja autonomia não se encontra em sua plenitude, em razão das precariedades decorrentes da má gerência dos recursos pelo Estado burguês. 


\section{REFERÊNCIAS}

Aula proferida pelo Professor Alexandre Rocha, na disciplina de Direito Penal Contemporâneo da Professora Maria Auxiliadora Minahim, na pós-graduação da Faculdade de Direito da Universidade Federal da Bahia, em 08/12/2014.

BRASIL. http://www12.senado.leg.br/noticias/materias/2015/04/15/seminario-debate-projetode-ana-amelia-para-agilizar-liberacao-de-pesquisas-clinicas, Acesso em 10/08/2015.

BRITO, Laura Souza Lima e. Liberdade e Direitos humanos: fundamentação jusfilosófica de sua universidade. São Paulo; Saraiva, 2013.

COX, Gracy. Compreender Sartre; Tradução de Hélio Magri Filho. Petrópolis: RJ: Vozes, 2007, p. $17-85$.

FERRAZ JUNIOR, Tercio Sampaio. Estudos de Filosofia do Direito: reflexões sobre o poder, a liberdade, a justiça e o direito. São Paulo: Atlas, 2003, p., 85.

FILHO, Pedro Lins Palmeira Filho. PAN, Simon Shi Koo. Cadeia farmacêutica no Brasil: avaliação preliminar e perspectivas. Sem ano, p.12.

GALUPPO, Marcelo Campos. Igualdade e diferença: Estado Democrático de Direito a partir do pensamento de Habermas. Belo Horizonte: Mandamentos, 2002. p., 10-23.

GOMES, Renata de Pinho; PIMENTEL,Vitor Paiva; LANDIM, André Borges; PIERONI, João Paulo. Ensaios Clínicos no Brasil: competitividade internacional e desafios. Complexo Industrial de Saúde - Banco Nacional do Desenvolvimento. Disponível em http://www.bndes.gov.br/SiteBNDES/bndes/bndes_pt/Institucional/Publicacoes/Consulta_Ex pressa/Tipo/BNDES_Setorial/201209_02.html > Acesso em 27 ago.2013. p.08.

GRIMM, Viviane; CERVI, Gicele Maria. "Formação do Sujeito Autônomo": um jeito de olhar a escola na sociedade de controle.Atos de Pesquisa em Educação.v4. n1. (p.53-71), 2005.

HEGEL, G. W. F. Linhas fundamentais da filosofia do direito. Trad. de Marcos Lutz Müller, Campinas, São Paulo, IFCH/UNICAMP, textos didáticos nº. 32 - Maio, 1998.

HEIDEGGER. Martin. O que é Metafísica. São Paulo - SP: Abriel Cultural, 1983.

KOTTOW, Miguel. Participación informada em clínica e investigatión biomédica. Las múltiples facetas de La decision y el consentimiento informados. Unesco, Red Latinoamericana y Del Caribe de Bioética: Universidade Nacional de Colombia, 2007.

LAFER, Celso, Ensaios sobre a liberdade. São Paulo: Perspectiva, 2011

MELLO, Daisy Giffone de. A vulnerabilidade e suas Relações com a autonomia e a Pesquisa com seres humanos. Rio de Janeiro: Fundação Oswaldo Cruz, 2008, p.08. 
MELLO, Sebástian Borges de Albuquerque. O conceito material de culpabilidade. $O$ fundamento da imposição da pena a um indivíduo concreto em face da dignidade da pessoa humana. Salvador: JusPODIVM, 2010, p.24.

MIALLE, Michel. Introdução crítica ao Direito. $3^{\text {a }}$ ed. Lisboa: Editora Estampa, 2005.

SANTOS, Rafael Cleison Silva dos; SANTOS, Elinaldo da Conceição dos. Malária: cobaias humanas no Amapá. Estação científica.vol.1, n.2. Macapá, 2011, p. 143-150.

SARTRE, Jean-Paul. O Ser e o Nada - Ensaio de Ontologia Fenomenológica. Petrópolis RJ: Vozes, 2001. p. 530-547.

SCHRAMM, Fermin Roland. A dupla identidade da Bioética da Proteção na era da globalização. Conferência realizada no instituto Fernandes Figueira, na aula inaugural do Curso de Especialização em Bioética, em 17 de maio de 2008, p.21.

SEN, Amartya. Desenvolvimento como liberdade. Tradução Laura Teixeira Motta, revisão técnica Ricardo Donelli Mendes. São Paulo: Companhia das Letras, 2010.

SOARES, Ricardo Maurício Freire. O princípio constitucional da dignidade da pessoa humana: em busca do direito justo. São Paulo: Saraiva, 2010. 